WSRC-RP-91-909

GAUSSIAN DISPERSION AND DOSIMETRIC MODELING SENSITIVITY TO AREA-SPECIFIC 1982-86 METEOROLOGICAL DATA COLLECTED AT THE SAVANNAH RIVER SITE (U)

Westinghouse Savannah River Company Savannah River Site Aiken, SC 29808

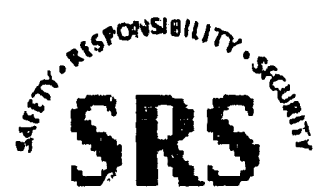

SAVANNAH RIVER SITE 


\section{DISCLAIMER}

This report was prepared as an account of work sponsored by an agency of the United States Government. Neither the United States Government nor any agency thereof, nor any of their employees, makes any warranty, express or implied, or assumes any legal liability or responsibility for the accuracy, completeness, or usefulness of any information, apparatus, product, or process disclosed, or represents that its use would not infringe privately owned rights. Reference herein so any specific commercial product, process, or service by the trade name, trademark, manufacturer, or otherwise. does not necessarily constitute or imply its endorsement, recommendation, or favoring by the United States Government or any agency thereof. The views and opinions of authors expressed herein do not necessarily state or reflect those of the United States Government or any agency thereof. 
WSRC-RP-91-909

DE92 016896

GAUSSIAN DISPERSION AND DOSIMETRIC MODELING SENSITIVITY TO AREA-SPECIFIC 1982-86 METEOROLOGICAL DATA COLLECTED AT THE SAVANNAH RIVER SITE

D.M. Hamby and M.J. Parker

September 13, 1991

Westinghouse Savannah River Company Savannah River Site

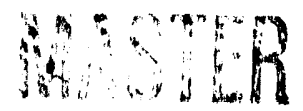
Aiken, SC 29808 


\section{CONTENTS}

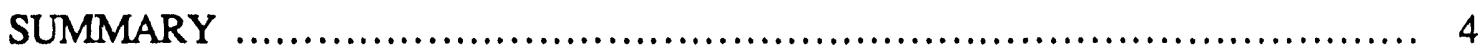

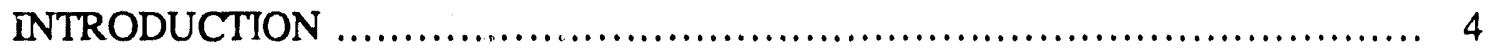

METEOROLOGICAL MONITORING AT SRS $\ldots \ldots \ldots \ldots \ldots \ldots \ldots \ldots \ldots \ldots \ldots \ldots$

COLLECTION AND MANIPULATION OF DATA $\ldots \ldots \ldots \ldots \ldots \ldots \ldots \ldots \ldots \ldots \ldots$

ATMOSPHERIC TRANSPORT AND DOSIMETRIC MODELING ............... 8

SENSITIVITY TO JOINT FREQUENCY DISTRIBUTIONS $\ldots \ldots \ldots \ldots \ldots \ldots \ldots \ldots 11$

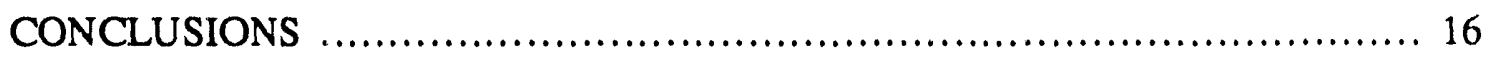




\section{LIST OF FIGURES}

1. Relative deposition as a function of distance determined by POPGASP $\ldots \ldots \ldots \ldots$

2. Annual average relative concentration as a function of distance determined by POPGASP 19

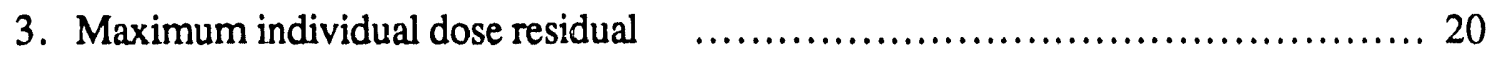

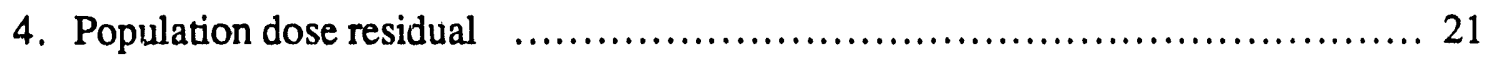

5. Annual average relative concentration as a function of distance determined by AXAIR89Q 22

6. Two-hour relative concentration as a function of distance determined by AXAIR89Q 23

7. Maximum individual dose residual from acute release $\quad \ldots \ldots \ldots \ldots \ldots \ldots \ldots \ldots \ldots . \ldots . \ldots 24$

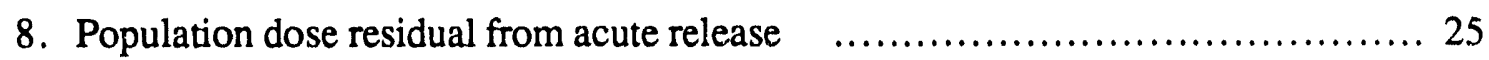

\section{LIST OF TABLES}

1. Meteorological parameters used in estimating the offsite maximum individual

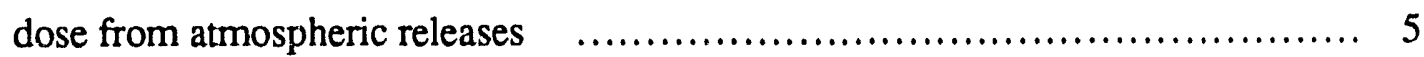

2. Distance from site center to meteorological towers $\ldots \ldots \ldots \ldots \ldots \ldots \ldots \ldots \ldots \ldots \ldots \ldots$

3. Meteorological data recovery for each of seven SRS onsite towers $\ldots \ldots \ldots \ldots \ldots . . . .6$

4. Maximum individual dose at the site boundary from a routine release for various meteorological datasets

5. Dose to the 50-mile population from a routine release for various meteorological datasets

6. Maximum individual dose at the site boundary from a non-routine release for various meteorological dataset

7. Dose to the 50-mile population from a non-routine release for various meteorological datasets 


\title{
GAUSSIAN DISPERSION AND DOSIMETRIC MODELING SENSITIVITY TO AREA-SPECIFIC 1982-86 METEOROLOGICAL DATA COLLECTED AT THE SAVANNAI' RIVER SITE
}

\author{
D.M. Hamby and M.J. Parker \\ Westinghouse Savannah River Company \\ Savannah River Site \\ Aiken, SC 29808
}

\section{SUMMARY}

Radiological dose to the offsite maximum individual or the 50-mile population is often estimated assuming that operational atmospheric releases originate from the geographical center of the Savannah River Site. Historically, meteorological data collected from instrumentation on the H-Area tower have been utilized to estimate atmospheric dispersion from centrally located "releases". This paper examines the effect on dose predictions using meteorological data from seven onsite towers located at $\mathrm{A}, \mathrm{C}, \mathrm{D}, \mathrm{F}, \mathrm{H}, \mathrm{K}$, and $\mathrm{P}$ areas to describe meteorological conditions at the central release location. Maximum individual dose estimates using both annual and short-term average air concentrations are well within $20 \%$ of the mean prediction. Population dose estimates are also within $20 \%$ of the mean except for two-hour doses using H-Area meteorological data, which is less than the average estimate by about $30 \%$.

\section{INTRODUCTION}

The environmental impacts from operations at the Savannah River Site are evaluated annually. These evaluations include analyses of offsite dose to a maximum individual and to the population residing within 50 miles. The SRS has a number of facilities which, through normal operations, release small amounts of radioactive materials to the atmosphere. These facilities are located at various points across SRS's 300-square-mile reservation. The majority of atmospheric effluents originate from reactors and separations facilities located near the Site center at distances greater than 5 miles from the Site boundary.

Critical to the estimation of downwind air concentration is the joint frequency distribution (JFD) of wind speed and stability as a function of wind direction. This computerized 
database is in the form of the number of meteorological observations for a given direction, speed, and stability. The JFDs used at the Savannah River Site are compiled from meteorological data collected over five-year periods. Data collected from 1982 to 1986 are analyzed in this report to determine the sensitivity of a straight-line gaussian dispersion model to five-year JFDs obtained from various locations on the SRS, in a region of noncomplex terrain characteristics.

To simplify dispersion modeling, releases of radionuclides to the atmosphere from the various SRS facilities are summed and assumed to be released from SRS's geographical center. This practice has occurred in the past for estimates of both maximum individual and population dose. Since 1989 the maximum individual dose has been calculated assuming 4 release locations as shown in Table 1. Additionally, atmospheric concentrations at offsite locations are determined using meteorological data from the H-Area tower.

Table 1. Meteorological parameters used in estimating the offsite maximum individual dose from atmospheric releases.

\begin{tabular}{ccccc}
\hline & \multicolumn{2}{c}{ Plant Coordinates } & & $\begin{array}{c}\text { Release } \\
\text { Number }\end{array}$ \\
Easting & Northing & Area & Height (m) \\
\hline & & & & \\
2 & 58000 & 62000 & Center & 62 \\
3 & 50041 & 104828 & M & 0 \\
4 & 20938 & 65284 & D & 16 \\
& 51863 & 106670 & A & 31 \\
\hline
\end{tabular}

Population doses are estimated assuming all nuclides are released from the center of the Site at a height of 62 meters. This assumption of a central release point for estimating population dose is valid because of the large distances between actual release points and the 50-mile population. Traditionally, the meteorological database accessed by the atmospheric dispersion modeling software has been that collected from the H-Area met tower, the closest tower to the SRS center. This report examines the dose assessment sensitivity to the meteorological data used in determining atmospheric transport (i.e., changes in dose estimates resulting from the use of meteorological data from the various onsite towers). 
Maximum individual and population doses have been calculated for atmospheric releases from the center of the SRS (E58000; N62000) for each of seven joint frequency distributions. All other parameter values were held constant to determine the dose sensitivity to meteorological data.

\section{METEOROLOGICAL MONITORING AT SRS}

The meteorological monitoring program at SRS has been developed by the Environmental Technology Section (ETS). Guidelines for developing this program have been primarily derived from Department of Energy Order 5400.6. Additional guidance has been obtained from the Nuclear Regulatory Commission, the Environmental Protection Agency, the American Nuclear Society, and the American Meteorological Society. The principle reason for creating this program is to provide current, accurate meteorological data to be used as input for estimating dispersion of an atmospheric release. This is an integral part of the emergency response capability at SRS. There are, however, many other uses for meteorological data at SRS; dosimetric calculations are made using the meteorological data base and site specific forecasts are made to assist in the many on-site operations which are dependent on prevailing weather conditions.

To accomplish the many goals of the meteorological monitoring program, eight 61 meter instrumentation towers have been erected on-site. Each of eight towers is located by a major facility. The redundancy of this network of meteorological towers ensures representative data collection even under adverse weather conditions or the loss of a tower. Sites for the A, C, D, F, H, K, and P-Area towers were chosen in 1972; an additional tower was placed in L-Area in 1985. The basic requirements for each tower were: (1) locations within 0.5 miles of each operational production facility, (2) instrumentation situated above relatively undisturbed forest, (3) towers located at elevations similar to that of nearby facility, and (4) measurements taken at a height of 200 feet above ground level (corresponding to the height of the major onsite process stacks). Physical locations of the meteorological towers and their relation to the site center are given in Table 2. From 19781988, the ETS meteorological monitoring program was enhanced considerably with upgrades to new, more stable towers, more sophisticated, sensitive and reliable meteorological instrumentation and communications hardware, and more powerful minicomputers. 


\section{COLLECTION AND MANIPULATION OF DATA}

For the period of this study (1982-1986), wind speed and azimuth/elevation angles were measured with MRI Vector Vanes. Data collection is performed in a similar manner for the meteorological instrument on each tower. Data signals were sampled at 1.5 second intervals and then archived as 15 minute averages. All data processing was performed by a centrally located minicomputer. Hourly averages were calculated and used in producing the 1982-86 meteorological databases for dispersion modeling.

Table 2. Distance from Site Center to Meteorological Tower

\begin{tabular}{|c|c|c|c|c|}
\hline \multirow[b]{2}{*}{ Tower* } & \multirow[b]{2}{*}{ Base Elevation ( $\mathrm{ft}$ ) } & \multirow[b]{2}{*}{ Site Coordinates } & \multicolumn{2}{|c|}{ Location Relative to Center } \\
\hline & & & Distance (mi) & Direction \\
\hline Center & 340 & E58000; N62000 & - & - \\
\hline A & 358 & E50950; N107590 & 8.7 & NW \\
\hline $\mathrm{C}$ & 303 & E47900; N66160 & 2.1 & WSW \\
\hline $\mathrm{D}$ & 142 & E21330; N67170 & 7.0 & WSW \\
\hline $\mathrm{F}$ & 290 & E50800; N76770 & 3.1 & WNW \\
\hline $\mathrm{H}$ & 300 & E66770; N66840 & 1.9 & NNE \\
\hline K & 267 & E41290; N51710 & 3.7 & SSW \\
\hline $\mathbf{P}$ & 306 & E66330; N41460 & 4.2 & ESE \\
\hline
\end{tabular}

* the L-Area met. tower did not begin collecting data until 1985.

Turbulence was measured directly by calculating the standard deviation of wind azimuth angle and elevation angle. Hourly averaged stability measurements may likely include directional changes in addition to turbulence resulting in artificially high sigmas and greater dispersion estimates in the transport models.

Five-year joint frequency distributions (JFDs) are created from raw measurements of wind speed and stability. The JFDs are used in EDG dispersion models to estimate relative air concentrations and deposition at various offsite locations. The D-Area 1982-86 JFD does not include nocturnal data since the tower is located in a river valley (see Laurinat 1987). Commonly at night, airflow at D-Area is affected by the local terrain of the Savannah River 
valley. Data gathered during these times is appropriate to use with local dispersion calculations but not for calculations of dispersion at large downwind distances.

The raw wind measurements from the various site towers are subjected to several quality assurance checks before the data are archived or converted to joint frequency distributions (Laurinat 1987). Real-time checks of the incoming data include screening for directional consistency among towers and verification that signal voltages are in the acceptable range. Fifteen-minute averages are also checked to ensure that a minimum number of valid measurements are recorded during the period. If all real-time QA checks on a given hour's data are passed, the hourly statistics are accumulated and archived on magnetic tape. Additional statistical tests are employed to remove outliers. The Dixon $r_{10}$ ratio test (Dixon 1957 ) is used to reject both small and large outliers with a confidence level of $99 \%$.

Table 3 lists data recovery by percentage for each tower. The average rejection rate for all towers was $21 \%$. Fourteen percent was removed by the real-time $\mathrm{QA}$ algorithm, $5 \%$ by the Dixon test, and $2 \%$ by comparison checks against expected turbulence values (Laurinat, 1987). By late 1987, a more robust meteorological data acquisition system was installed. This included new, more sensitive and reliable meteorological instrumentation. The MRI Vector Vane was replaced at each tower by a Teledyne Geotech bivane and cup anemometer. Data recovery now averages better than $90 \%$ annually. Updated meteorological databases for each area are currently being created. Modeled dispersion characteristics using the new databases will be more heavily weighed toward low wind speed, very stable conditions; previously, these meteorological observations were discarded as outliers.

\section{ATMOSPHERIC DISPERSION AND DOSIMETRIC MODELING}

Widely accepted dispersion and dosimetric models are utilized to estimate the offsite impacts of routine and non-routine atmospheric releases at the SRS. These model algorithms are contained in software developed by the NRC; XOQDOQ predicts relative air concentrations and relative deposition at downwind receptor locations and GASPAR generates estimates of dose resulting from such concentrations. These two codes have been combined at the SRS to produce two dose assessment packages called MAXIGASP and POPGASP, used to estimate maximum individual and population doses, respectively. 
Table 3. Meteorological data recovery for each of seven SRS onsite towers.

Area $\quad \%$ Recovery

Atmospheric modeling includes the determination of downwind air concentrations as well as ground surface concentrations from deposition. Downwind relative concentrations are estimated using a Gaussian plume model (see NRC 1977b) characterized by,

$$
\frac{\bar{\chi}}{Q}(x, k)=\frac{2.032}{x} \sum_{i j} \frac{f_{i j}(k)}{\bar{U}_{i}(x) \sigma_{z j}(x)} e^{\left(\frac{-h_{0}^{2}}{2 \sigma_{z} x^{2}}\right)}
$$

where,

$$
\begin{aligned}
\frac{\bar{\chi}}{\mathrm{Q}}(\mathrm{x}, \mathrm{k})= & \text { average air concentration per unit release at distance } \mathrm{x} \text { in sector } \mathrm{k} \\
& \left(\mathrm{sec} / \mathrm{m}^{3}\right) \\
\overline{\mathrm{U}}_{\mathrm{i}}(\mathrm{x})= & \text { mid-point value of the ith wind-speed class }(\mathrm{m} / \mathrm{sec}) \\
\sigma_{\mathrm{zj}}(\mathrm{x})= & \text { vertical plume spread }(\mathrm{m}) \\
\mathrm{h}_{\mathrm{e}}= & \text { effective plume height }(\mathrm{m})
\end{aligned}
$$

Plume depletion and radioactive decay corrections are not considered for the examples in this report. Likewise, to ensure conservatism, depletion and decay are not considered in annual estimates of offsite impact at the SRS. Deposition on ground surfaces is estimated but it is assumed that deposition does not deplete the passing plume. Ground deposition is determined using, 


$$
\overline{\bar{D}}(x, k)=\frac{\sum_{i j} D_{i j} f_{i j}(k)}{\frac{2 \pi x}{16}}
$$

where,

$$
\begin{aligned}
\frac{\overline{\mathrm{D}}}{\mathrm{Q}}(\mathrm{x}, \mathrm{k}) & =\text { average relative deposition per unit area at distance } \mathrm{x} \text { in sector } \mathrm{k}\left(\mathrm{m}^{-2}\right) \\
\mathrm{x} & =\text { downwind distance }(\mathrm{m}) \\
\mathrm{k} & =\text { wind direction, } \mathrm{k}^{\text {th }} \text { sector } \\
\mathrm{D}_{\mathrm{ij}} & =\text { relative deposition rate }\left(\mathrm{m}^{-1}\right) \\
\mathrm{i} & =\mathrm{j}^{\text {th }} \text { wind speed } \\
\mathrm{j} & =\mathrm{j}^{\text {th }} \text { stability category } \\
\mathrm{f}_{\mathrm{j} j}(\mathrm{k}) & =\text { probability of } \mathrm{i}^{\text {th }} \text { wind speed and } \mathrm{j}^{\text {th }} \text { stability in the } \mathrm{k}^{\text {th }} \text { sector }
\end{aligned}
$$

The relative deposition rate, as a function of release height, is determined from Figures 7 through 10 of Regulatory Guide 1.111 (NRC 1977b). The buildup effects from recirculation and stagnation are not considered in either model. (See Bauer 1991 for more detail on relative air concentration and deposition calculations as performed by XOQDOQ).

The atmospheric release exposure pathways to man include inhalation, ingestion, plume gamma-shine, and ground shine. The inhalation and ingestion dose models are rather straight-forward in that dose is described as being directly proportional to intake. Concentrations of radionuclides in the atmosphere and in foodstuffs are determined using models found in the the NRC Regulatory Guide 1.109 (NRC 1977a).

Plume gamma-shine is considered only for noble gases since the majority of the plume shine dose is delivered by these nuclides. Photon emissions are grouped by energy with each photon intensity weighted by its energy and energy absorption coefficient. Integrated exposures from each energy group are summed to predict total dose rates from airborne gamma-emitting noble gases.

Doses resulting from ground contamination are determintd from ground plane dose conversion factors. It is assumed, by the use of these factors, that the contamination is uniform over the surface from which exposed. A factor is included in the calculation to account for structural shielding during occupancy. Regulatory Guide 1.109 (NRC 1977a) 
should be reviewed for a more detailed description of the dosimetric models described here and utilized in GASPAR.

\section{SENSITIVITY TO JOINT FREQUENCY DISTRIBUTIONS}

Gaussian dispersion model sensitivity to joint frequency distrbutions obtained at the SRS was measured by predicting offsite dose to a maximum individual at the site boundary and to the $80-\mathrm{km}$ population. Each of seven meteorological databases, including arrays of joint frequency distribution and mean wind speed, was used in the MAXIGASP, POPGASP, and AXAIR89Q computer codes. MAXIGASP and POPGASP dose predictions were determined using telease data representative of years during reactor and separations operations. This, however, will not affect the conclusions of this study since relative variations in dose are evaluated. AXAIR 59 only considers the inhalation and plumeshine pathways, therefore, dose estimates from non-routine releases were determined using AXAIR89Q and a source term of tritium and xenon- 133 .

All release scenarios for routine and non-routine releases were identical with the exception of meteorological database. Releases were assumed to originate at the geographical center of the SRS at a height of 62 meters; variations in terrain as a function of distance were therefore consistent for all scenarios. Flat terrain and actual terrain features were considered for the routine and non-routine releases, respectively.

Routine Releases. Doses delivered to offsite populations by atmospheric releases are dominated in this scenario by tritium, Ar-41, I-129, and Cs-137. This requires that both ground deposition and air concentration be examined for variations with distance. Onsite met databases from seven areas including; $\mathrm{A}, \mathrm{C}, \mathrm{D}, \mathrm{F}, \mathrm{H}, \mathrm{K}$, and $\mathrm{P}$ are utilized for the determination of maximum individual and 50-mile population close.

Annual average predicted values of relative deposition are given as a function distance in Figures 1. Values were determined for the WNW sector (toward Augusta) using POPGASP. At distances less than 5 miles estimates of relative deposition are nearly identical regardless of the meteorological database used in the calculations. From 10 to 50 miles the range of deposition values appears constant, about $35 \%$ of the mean value.

Relative air concentrations at ground level are also given for the WNW sector. Figure 2 shows that variations in air concentration at distances out to 50 miles are also relatively 
insensitive to the meteorological data collected from various locations on the Savannah River Site. Concentration predictions vary with a range that is again about $35 \%$ of the mÆan at 50 miles.

Since relative, not absolute, dose estimates are of concern in this report, variation in dose predictions are presented as residuals about the mean dose from all seven predictions. Figure 3 is a plot of residual dose values for the maximum individual estimates. The classifications along the $\mathrm{x}$-axis refer to the seven meteorological databases for the 1982-86 period. The plot shows that the maximum dose estimates are all within $20 \%$ of the mean dose and, with the exception of $\mathrm{H}$ - and F-Areas, predictions are within approximately $3 \%$ of the mean.

Table 4. Maximum individual dose at the Site boundary for various meteorological datasets (routine release).

Met. Database Sector of MI Dose (mrem)

$\begin{array}{ccc}\text { A } & \text { E } & 0.66 \\ \text { C } & \text { E } & 0.64 \\ \text { D } & \text { E } & 0.63 \\ \text { F } & \text { E } & 0.71 \\ \text { H } & \text { E } & 0.55 \\ \text { K } & \text { WSW } & 0.64 \\ \text { P } & \text { E } & 0.62\end{array}$

Average $\quad 0.64$

$1 \sigma$ Std. Dev. 0.048

Table 4 shows dose estimates when using the various databases. When using the seven onsite meteorological databases, the maximum individual dose estimates average 0.64 mrem with a standard deviation of 0.048 . Generally, the maximum individual is located in the East sector. However, use of the K-Area meteorological database results in locating the maximum individual in the West Southwest sector. This does not cause the dose prediction to deviate from the other estimates. 
The residuals of population dose estimates are shown in Figure 4. Population ciose estimates are well within 20\%. Population dose estimates are given in Table 3 for each met database. The use of $\mathrm{K}$-Area met data results in the largest population dose, $6 \%$ greater than the mean of 32 person-rem.

Table 5. Dose to the 50-mile population for various meteorological datasets (routine release).

Met. Database

Dose (person-rem)

$\begin{array}{ll}\text { A } & 31 \\ \text { C } & 32 \\ \text { D } & 32 \\ \text { F } & 31 \\ \text { H } & 31 \\ \text { K } & 33 \\ \text { P } & 30\end{array}$

Average $\quad 32$

$1 \sigma$ Std. Dev. 1.1

Non-Routine Releases. A maximum individual dose and a sector-specific population dose were estimated for each 1982-86 five-year meteorological database. The source term includes tritium $(2200 \mathrm{Ci})$ and xenon-133 $(3700 \mathrm{Ci})$ releases expected in a reactor charge/discharge accident involving the melting of one tritium producing assembly. These two nuclides are among 21 others expected to be released to the atmosphere during this type of accident (Bickford 1991). Only tritium and xenon were chosen for three reasons: (1) they would dominate the dose, (2) tritium exercises the inhalation models and xenon exercises the plume-shine models, and (3) only relative dose estimates are necessary to determine AXAIR89Q's sensitivity to meteorology input. 
The AXAIR89Q code calculates both 2-hour and annual average air concentrations at various distances downwind of the release point. Deposition is not determined in AXAIR89Q. Annual average relative air concentrations in the WNW sector as a function of distance are shown in Figure 5. Annual concentrations, like those determined using POPGASP, differ by about $30 \%$ at a distance of 50 miles. The concentrations in Figure 5 are greater than those in Figure 2 because AXAIR89Q is considering increases in terrain. At distances of 40 to 50 miles, ihe terrain in the WNW sector increases by about 200-300 feet. This increase in elevation results in a decrease in the relative plume height and, therefore, the increase in ground-level air concentration.

Relative air concentrations for a two-hour release are given in Figure 6. These values are 99.5th percentiles and are expected to be exceeded only $0.5 \%$ of the time. Generally, the concentration curves 're similar to the annual average curves except that concentrations are approximately two orders of magnitude larger. The high and low two-hour concentrations at 50 -miles differ by about $50 \%$.

At distances less than 5 miles and between 30 and 40 miles some of the curves deviate from smooth exponential decreases. These "perturbations" are the result of the method for choosing 99.5th percentiles. For example, the noticeable concentration decrease between 30 and 40 miles using D-Area met data occurs because the 30-mile 99.5th percentile concentration is determined from neutral (D) stability conditions while the 40-mile concentration results from unstable (C) conditions. The "effective" instability at 40 miles results in more mixing and therefore a lower two-hour concentration.

Residuals of the maximum individual dose predictions for a two-hour release are presented in Figure 7. The dose estimate using A-Area data is approximately $15 \%$ lower than the mean. The range of maximum dose values is about $27 \%$ of the mean value.

Predictions of maximum individual dose and the location of the hypothetical maximum individual are given in Table 6. Even though the maximum individual's location varies, the dose estimates are relatively insensitive to meteorological data. The standard deviation is slightly less than $10 \%$ of the mean. 
Table 6. Maximum individual dose at the Site boundary for various meteorological datasets (acute release).

\begin{tabular}{ccc}
\hline Met. Database & Sector of MI & Dose (mrem) \\
\hline & & 0.22 \\
A & E & 0.29 \\
C & NNW & 0.25 \\
D & NW & 0.26 \\
F & E & 0.26 \\
H & NNW & 0.29 \\
K & NNW & 0.26 \\
P & NNW & 0.26 \\
& & Average \\
& \multicolumn{2}{c}{ 1 $\sigma$ Std. Dev. 0.024} \\
\hline
\end{tabular}

Generally, population dose estimates were determined for individuals in the WNW sector. The NW sector was selected when using the A- and $\mathrm{H}$-Area meteorological data. These two sectors include the city of Augusta and contain the following number of people within 50 miles: (1) NW sector pcpulation $=125261 ;$ (2) WNW sector population $=170002$.

Table 7 presents estimates of population dose and Figure 8 is a plot of population dose residuals. Dose predictions are within $20 \%$ of the mean except when using the H-Area JFD. The use of H-Area met data results in estimates that are $30 \%$ less than the average estimate. The $\mathrm{H}$-Area data also, however, predicts that the maximum population dose will be delivered when the wind blows toward the northwest. The dose estimate using $\mathrm{H}$-Area meteorology would be increased to 2.4 if it were normalized by population (170002+ 125261 ). The range of high to low dose predictions is about $48 \%$ of the mean prediction. 
Table 7. Dose to the 50-mile population for various meteorological datasets (acute release).

\begin{tabular}{ccc}
\hline Met. Database & Population Sector & $\begin{array}{c}\text { Dose } \\
\text { (person-rem) }\end{array}$ \\
\hline & & \\
A & NW & 2.5 \\
C & WNW & 2.8 \\
D & WNW & 2.9 \\
F & WNW & 3.0 \\
H & NW & 1.8 \\
K & WNW & 3.1 \\
P & WNW & 2.6 \\
& & Average \\
& & 2.7 \\
& & 16 Std. Dev. 0.43 \\
\hline
\end{tabular}

\section{CONCLUSIONS}

The dispersion and dosimetric models used at the Savannah River Site for estimates of environmental impact appear to be insensitive to five-year averaged joint frequency distributions generated by meteorological data collected from various unsite towers. Maximum individual dose estimates using both annual and short-term average air concentrations are well within $20 \%$ of the mean prediction. Population dose estimates are also within $20 \%$ of the mean except for two-hour doses using H-Area met data, which is less than the average estimate by about $30 \%$. Considering all other sources of uncertainty, these variations are seen as/negligble. Environmental dose estimates resulting from centrally located releases could essentially be determined using JFDs generated by data from any of the SRS towers. 


\section{REFERENCES}

Bauer, L.R., "Modelling Chronic Atmospheric Releases at the SRS: Evaluation and Verification of XOQDOQ", WSRC-RP-91-320, Westinghouse Savannah River Company, Savannah River Laboratory, Aiken, SC, 1991.

Bickford, W.E., Hootman, H.E., and Weingardt, J.J. (compilers), "New Production Reactor at Savannah River", WSRC-RP-89-262, Vols. 1, 2, and 3, Ver. 3, April 1991.

Dixon, W.J., and Massey, F.J., Introduction to Statistical Analysis, 2nd ed., McGrawHill, New York, pgs. 275-278, 412, 1975.

Laurinat, J.E., "Average Wind Statistics for SRP Ared Meteorological Towers", DPST-87341, Westinghouse Savannah River Company, Savannah River Laboratory, Aiken, SC, 1987.

U.S. Nuclear Regulatory Commission, "Regulatory Guide 1.109: Calculation of Annual Dose to Man from Routine Releases of Reactor Effluents for the Purpose of Evaluating Compliance with 10 CFR Part 50, Appendix I", Revision 1, October 1977a.

U.S. Nuclear Regulatory Commission, "Regulatory Guide 1.111: Methods for Estimating Atmospheric Transport and Dispersion of Gaseous Effluents in Routine Releases from Light-Water-Cooled Reactors", Revision 1, October 1977b. 


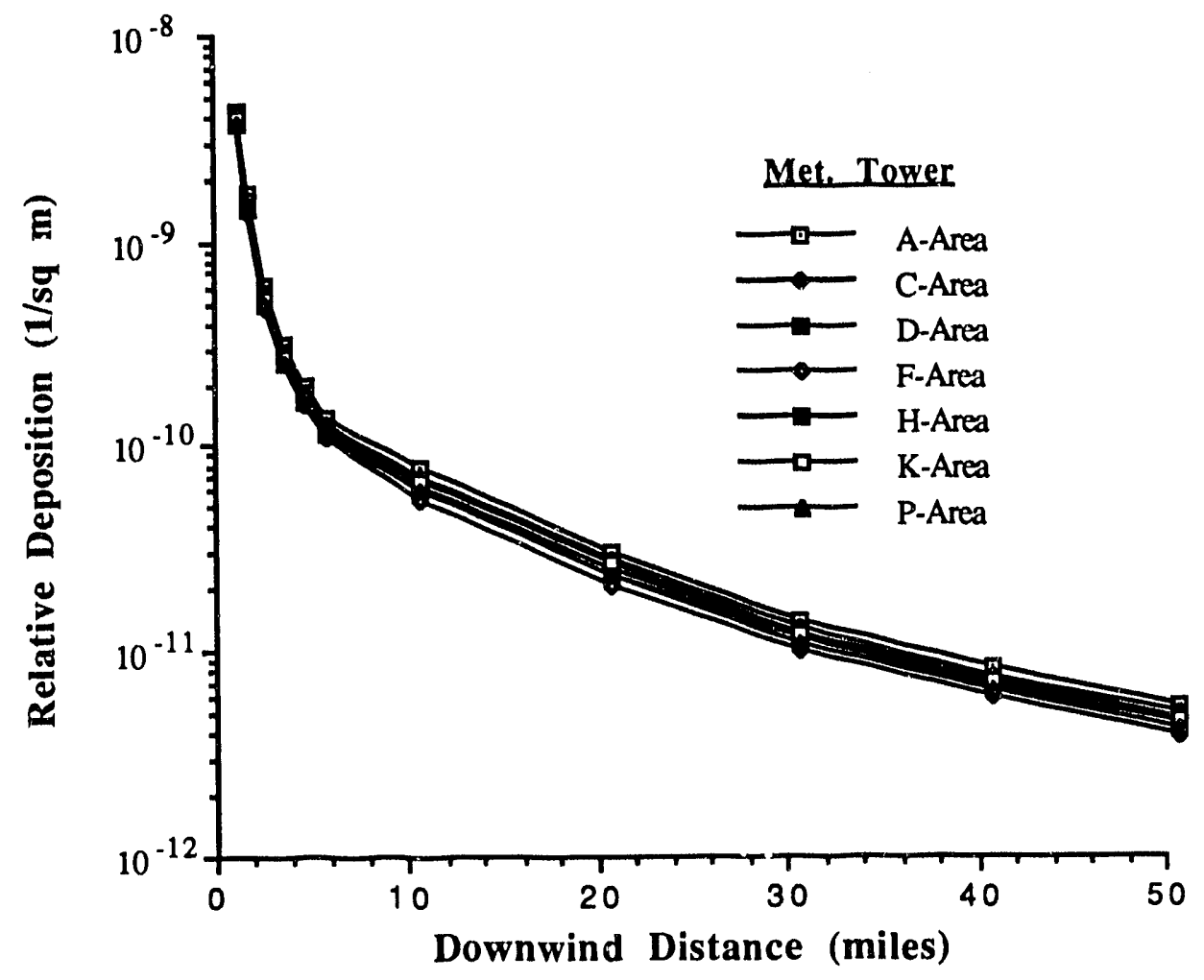

Figure 1. Relative deposition as a function of distance. Annual average values given for the WNW sector taken from POPGASP. 


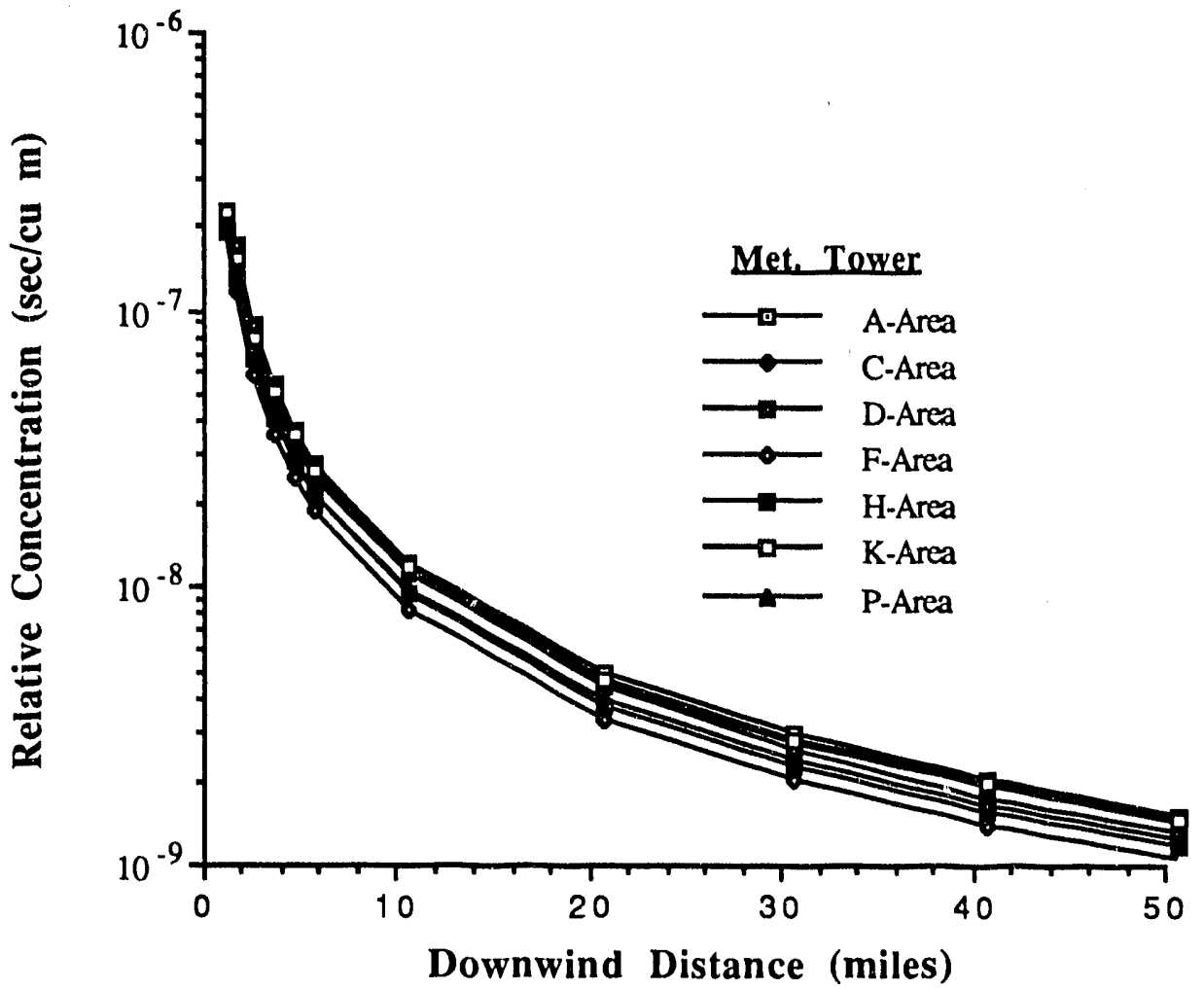

Figure 2. Relative concentration as a function of distance. Annual average values in the WNW sector taken from POPGASP. 


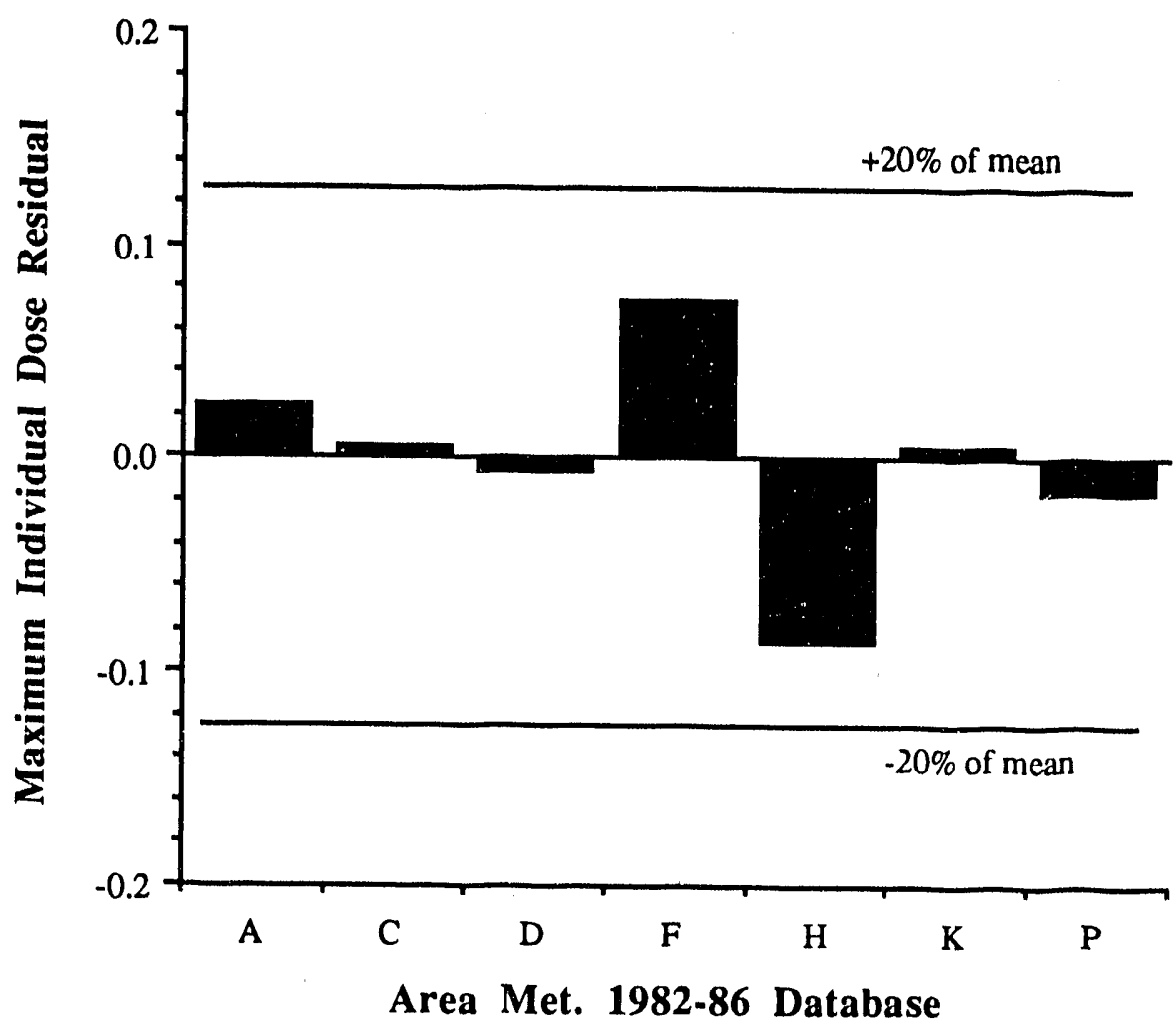

Figure 3. Maximum individual dose residuals. 


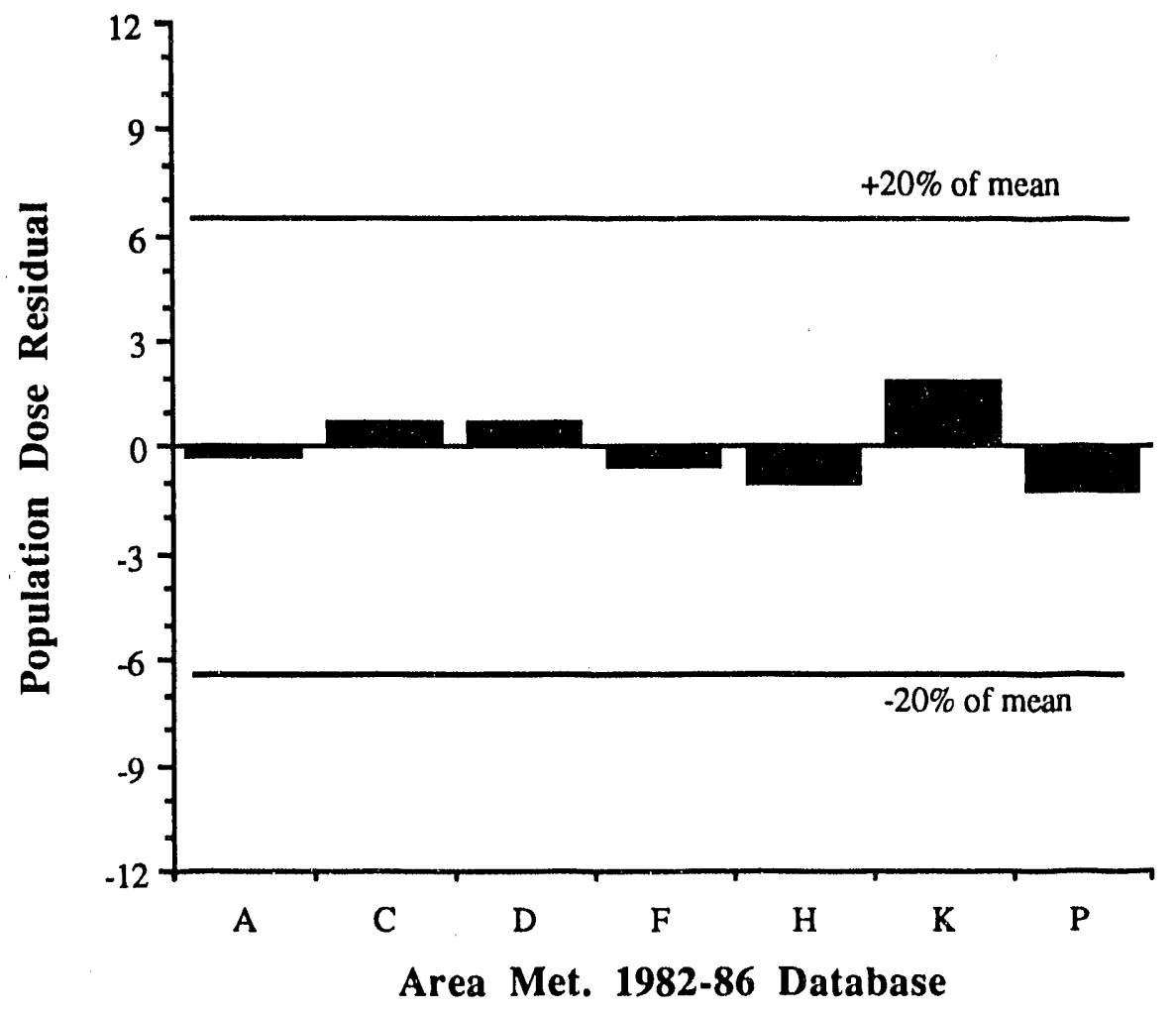

Figuse 4. Population dose residuals. 


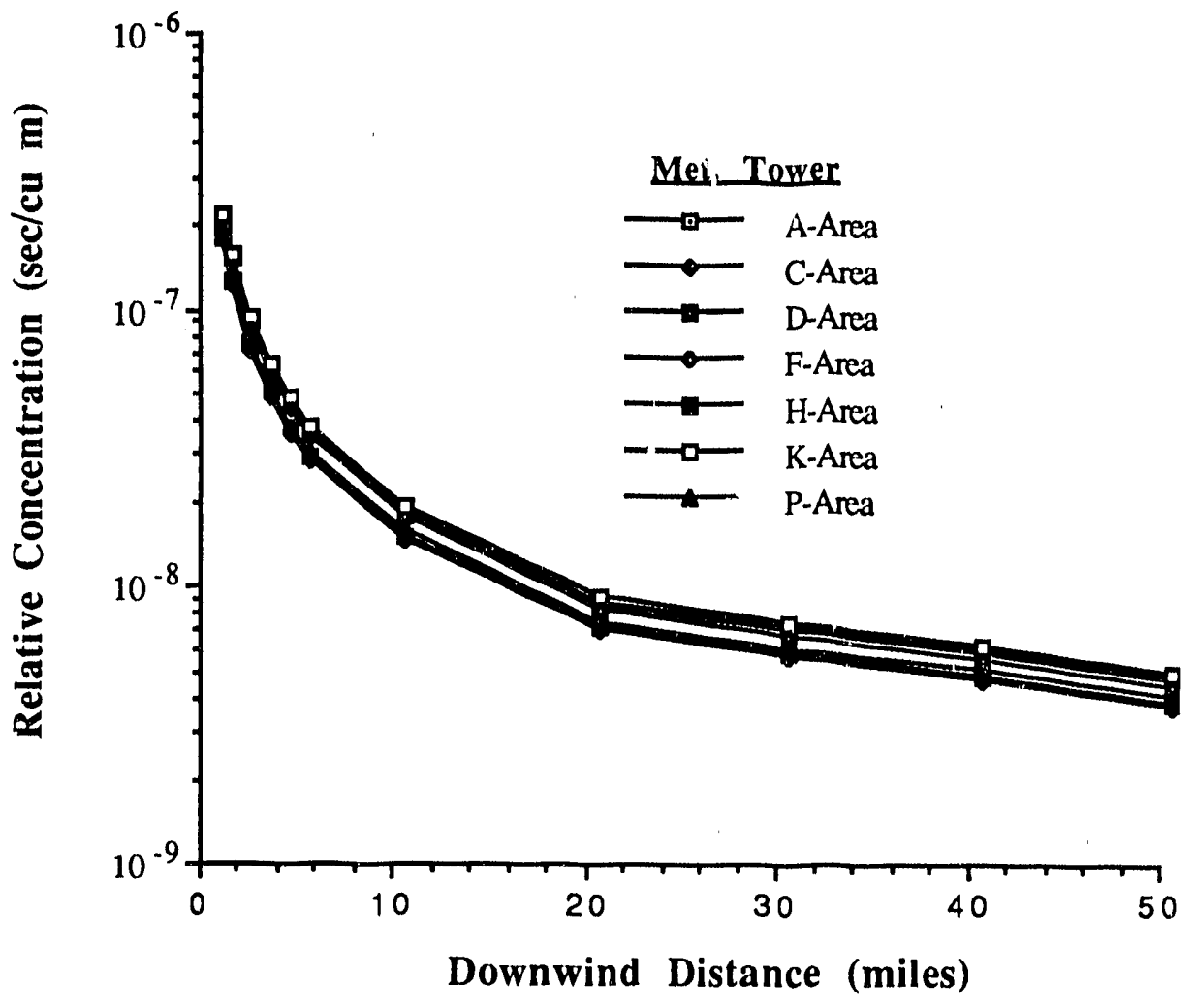

Figure 5. Relative concentration as a function of distance. Annual average values in the WNW sector taken from AXAIR89Q. 


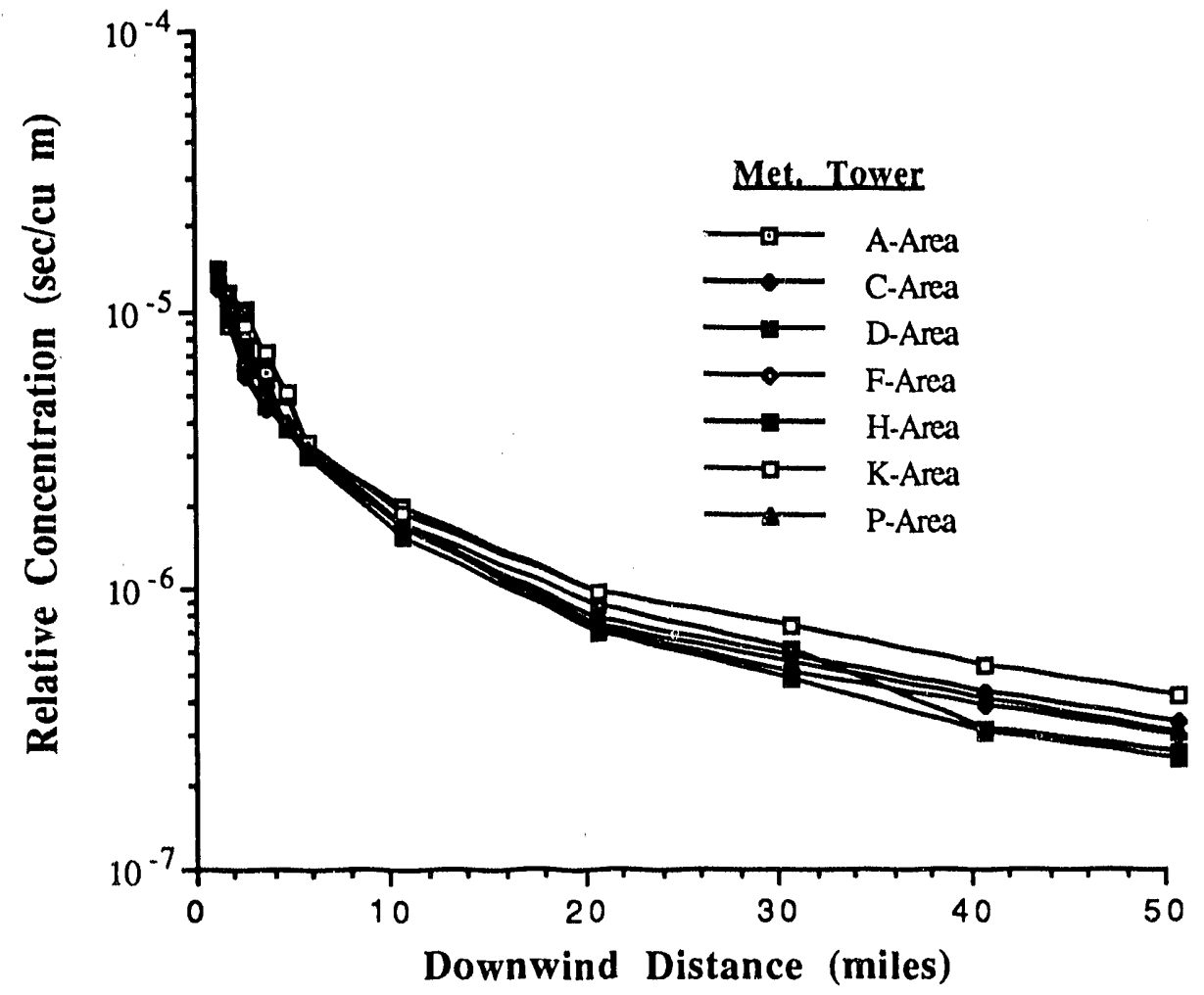

Figure 6. Relative concentration as a function of distance. Two-hour values in the WNW sector taken from AXAIR89Q. 


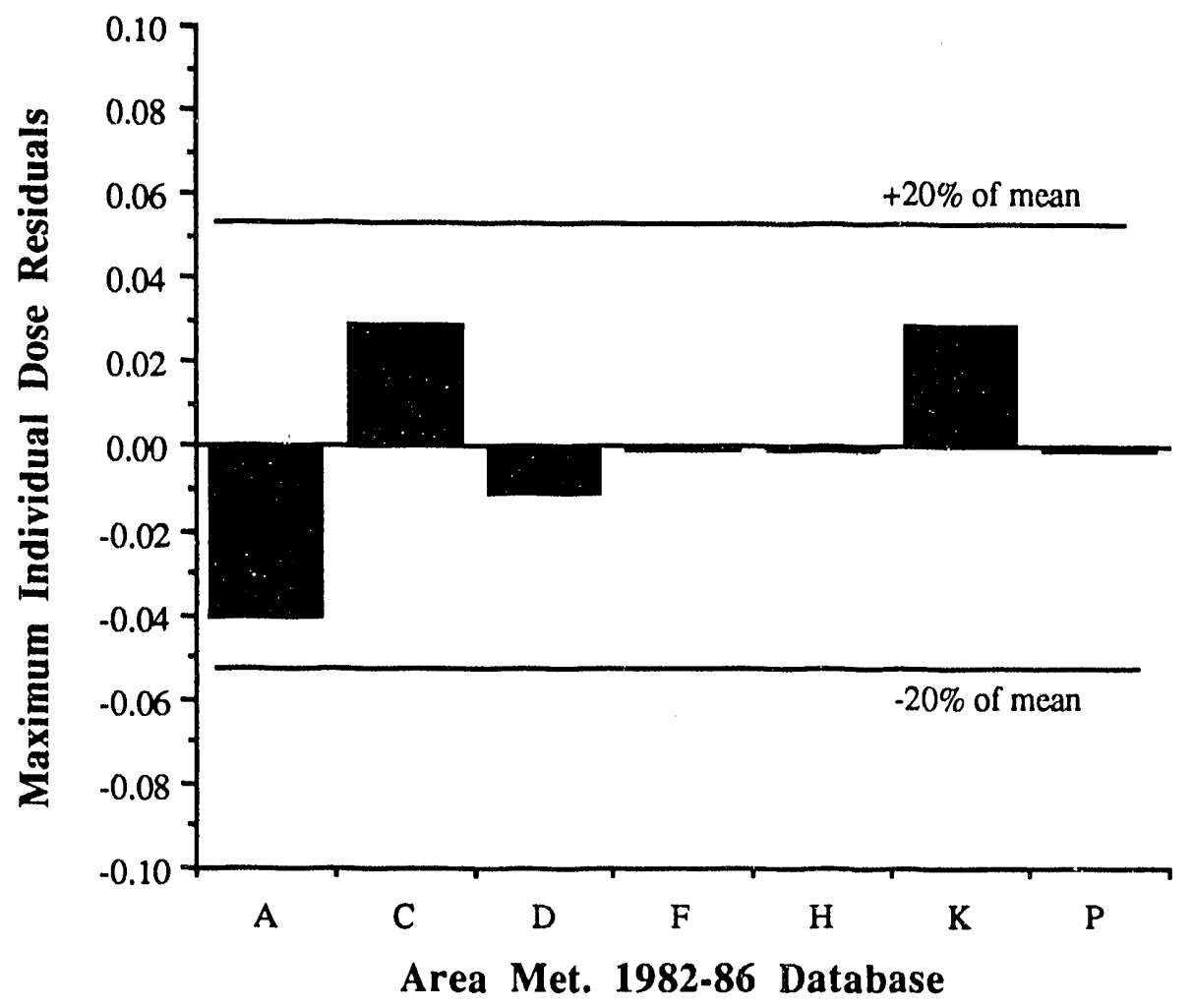

Figure 7. Maximum individual dose residuals from acute releases. 


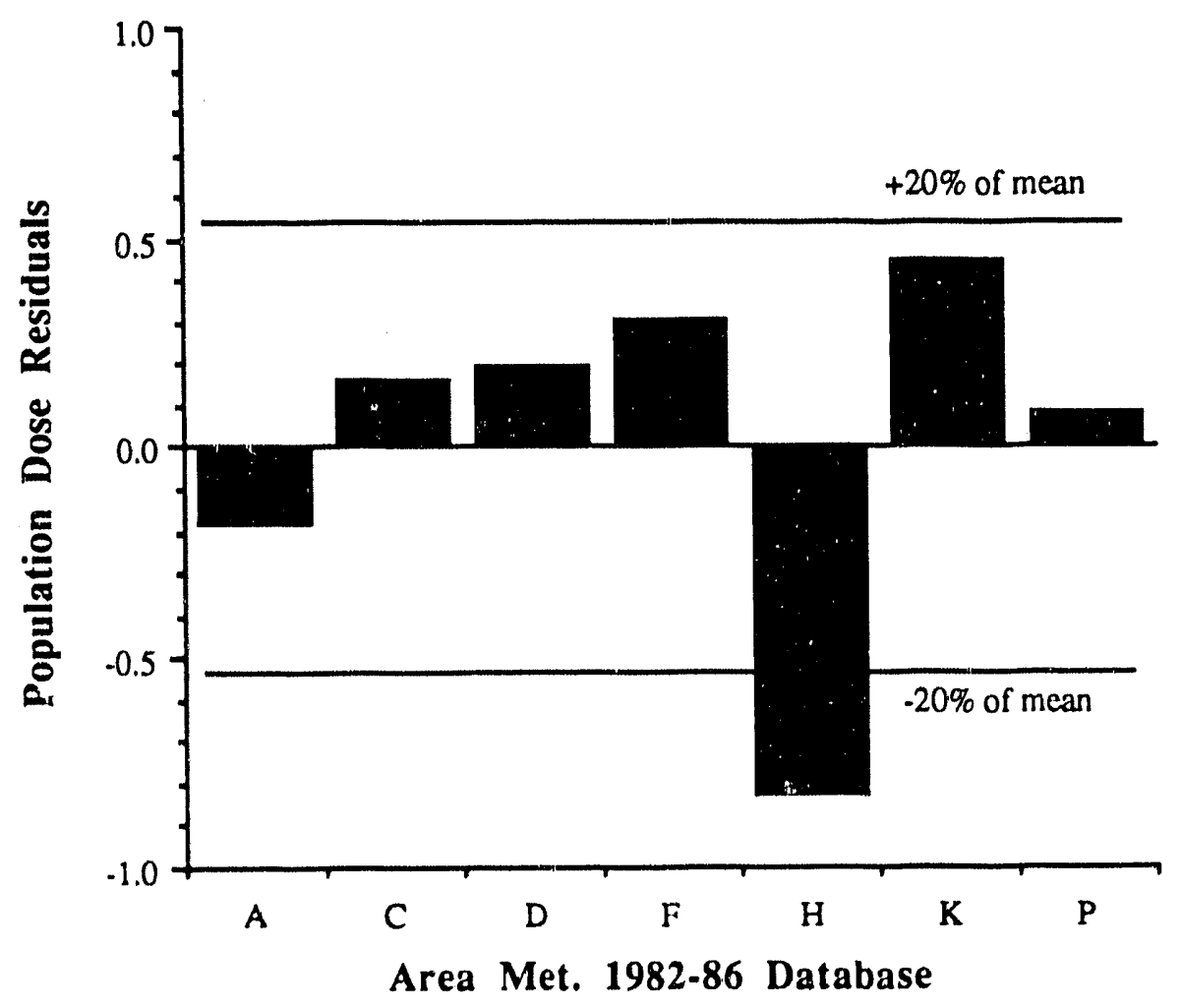

Figure 8. Population dose residuals from acute releases. 

